\begin{tabular}{|l|l|l}
\hline aM/a & $\begin{array}{c}\text { Construction and Material Journal } \\
\text { e-ISSN 2655-9625, http://jurnal.pnj.ac.id/index.php/cmi }\end{array}$ & $\begin{array}{l}\text { Volume 1 No.2 } \\
\text { Juli } 2019\end{array}$ \\
\hline
\end{tabular}

\title{
EVALUASI KINERJA STRUKTUR JEMBATAN TYPE VOIDED SLAB
}

\author{
Andi Indianto(1), Asep Hilmansyah(2) \\ ${ }^{I}$ Dosen Teknik Sipil, Politeknik Negeri Jakarta, Kampus UI Depok, email : andipoltek@gmail.com \\ ${ }^{2}$ Kaseksi Standar, Direktorat jembatan, Kementrian PUPR - Jakarta, email : aseph2000@yahoo.com
}

\begin{abstract}
ABSTRAK
Makalah ini memaparkan hasil penelitian kinerja struktur jembatan tipe voided slab. Penelitian ini dilakukan oleh adanya masalah terkelupasnya lapisan permukaan dan terbentuknya alur memanjang di permukaan lantai jembatan tipe voided slab. Tujuannya untuk mengevaluasi kinerja standar jembatan tipe pre-tensioned precast concrete voided slab bentang $16 \mathrm{~m}$, dengan tinjauan beban sesuai SNI 1725:2016 dan beban aktual. Dalam evaluasi ini dilakukan uji lendutan terhadap struktur jembatan voided slab ,untuk mengetahui lendutan yang terjadi pada struktur yang elemennya menyatu dan yang terpisah. Pendekatan teoritis dilakukan untuk mengetahui kinerja struktur terhadap beban aktual dan beban standar sesuai dengan SNI.1725:2016. Hasil uji menunjukkan bahwa jembatan voided slab yang lapisan permukaan lantainya terbentuk alur memanjang, terindikasi antar elemennya tidak menyatu, perbedaan lendutan antar elemen sebesar $8,9 \mathrm{~mm}$, dan terdiskripsi tidak layak. Bagian lapisan permukaan lantai jembatan yang tidak terbentuk alur memanjang, terindikasi antar elemen masih menyatu, perbedaan lendutannya sebesar $0,76 \mathrm{~mm}$, dan terdiskripsi layak. Hasil uji di lapangan juga menunjukkan bahwa bagian elemen voided slab yang tidak menyatu, terindikasi tidak layan menerima beban aktual, dengan lendutan sebesar 13,34 mm, lebih besar dari lendutan izin sebesar $7 \mathrm{~mm}$, dan bagian elemen voided slab yang menyatu, terindikasi layan menerima beban aktual, dengan lendutan sebesar 5,79 mm, lebih kecil dari lendutan izin sebesar $7 \mathrm{~mm}$. Hasil analisa teoritis menunjukkan bahwa struktur voided slab yang elemennya tidak menyatu, tidak layan menerima beban standar, dan struktur yang antar elemennya menyatu, dalam kondisi layan menerima beban standar. Kesimpulan pada evaluasi ini adalah struktur voided slab dapat berkinerja baik (layak dan layan) jika antar elemennya menyatu. Agar tetap menyatu, disarankan untuk dilakukan perubahan tipe ikatan antar elemen voided slab yang dapat memberikan jaminan ikatan selama umur rencana jembatan.
\end{abstract}

Kata kunci: Voided slab, menyatu, layak, layan.

\begin{abstract}
This paper presents the results of research on "the performance of the bridge structure voided slab type". The research on the performance of the bridge structure type voided slab was carried out due to the problem of peeling off the surface layer and the formation of a longitudinal groove on the deck surface voided slab type. This research was conducted with the purpose of evaluating the performance standard of pre-tensioned precast concrete type voided slab bridge $16 \mathrm{~m}$ span, with load reviews according to SNI 1725: 2016 loading regulations and actual loads. This research is to find out the deflection that occurs in structures with unified and separate elements. The test results show that the bridge's voided slab with the surface layer of the floor forming an elongated groove, indicating that the joint is not integrated, the deflection difference is $8.9 \mathrm{~mm}$, and it is not feasible. Parts of the bridge floor surface layer which do not form longitudinal grooves, indicating integrated, the deflection difference is $0.76 \mathrm{~m}$, and it is feasible. Test results also show that parts of the voided slab element are not integrated, indicating that can not accept the actual load, the deflection is $13.34 \mathrm{~mm}$, bigger than service deflection of $7 \mathrm{~mm}$, and the integrated part of the voided slab element indicate that it is serviceable to receive actual load, the deflection is $5.79 \mathrm{~mm}$, smaller than service deflection of $7 \mathrm{~mm}$. The results give a description that the voided slab structure whose elements are not integrated, not serviceable accepts the life load, and structures are integrated between elements, in conditions serviceable to standard loads.It can be concluded that voided slab structures can perform well (feasible and serviceable) if the elements are integrated. In order to stay integrated, it is recommended to change the type of bond between voided slab elements, which can provide bond guarantees for the life of the bridge plan.
\end{abstract}

Keywords: Voided slab, integrated, feasible, serviceable 


\section{PENDAHULUAN}

\subsection{Latar Belakang}

Salah satu produk beton pra-cetak untuk jembatan ber-bentang pendek yang banyak digunakan adalah Voided Slab. Struktur Jembatan Precast Voided Slab diproduksi dengan bentang $5 \mathrm{~m}$ sampai dengan $16 \mathrm{~m}$. Struktur Jembatan Precast Voided Slab digunakan dengan pertimbangan cepat dan mudah pelaksanaannya . Di sisi lain type voided slab sudah di standarisasikan oleh Direktorat Jenderal Bina Marga Kementrian PUPR, untuk bentang 5 sampai dengan 16 m. dengan BM 100. Standar voided slab yang ada, dibuat pada tahun 1980, masih menggunakan peraturan pembebanan sebelum PPJR 1987 (Peraturan muatan untuk jembatan jalan raya No. 12 / 1970.) , sehingga diperlukan updating standard struktur jembatan type pre-tensioned precast concrete voided slab sehubungan dengan telah diterbitkannya SNI 1725:2016 tentang pembebanan untuk jembatan. Masalah yang muncul pada jenis jembatan voided slab adalah terkelupasnya sebagian lapisan permukaan lantai jembatan dan terbentuknya alur memanjang di permukaan lantai jembatan, yang dapat membahayakan pengendara kendaraan roda dua.

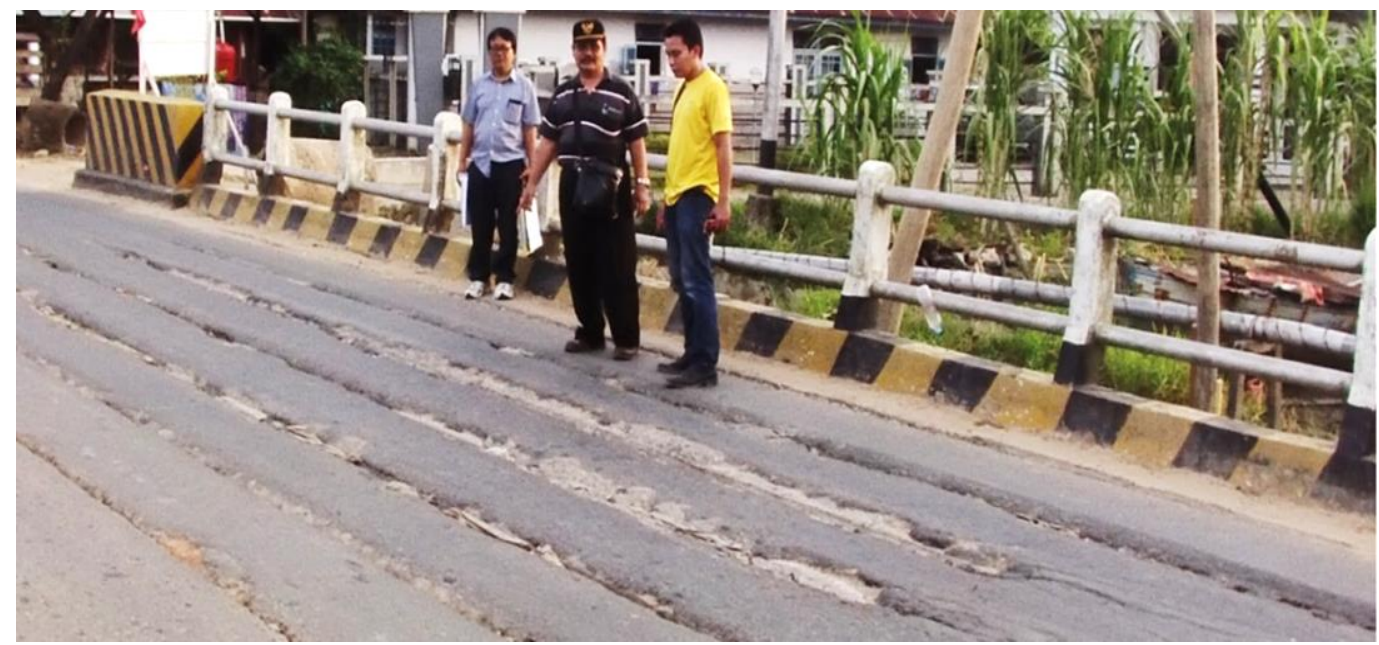

Gambar 1. Elemen struktur voided slab yang tidak menyatu

\subsection{Tujuan}

a. Mengevaluasi kinerja struktur (kelayakan dan kelayanan) jembatan type pretensioned precast concrete voided slab bentang $16 \mathrm{~m}$, dengan tinjauan beban sesuai peraturan pembebanan SNI 1725:2016 dan beban aktual maksimum yang mungkin terjadi di lapangan.

b. Memberikan saran penanganan terhadap kegagalan ikatan antara segmen voided slab.

\subsection{Tinjauan Pustaka}

\section{a. Struktur Jembatan Voided Slab}

Struktur jembatan voided slab adalah struktur yang tersusun dari plat-plat pracetak dengan penampang berlubang. Lubang-lubang di dalam penampang ini dimaksudkan untuk mengurangi berat sendiri dan efisiensi material. Penulangan di-dalam beton menggunakan system pra-tegang pre-tensioning. Untuk 
menyatukan antar elemen voided slab digunakan lateral stressing yang berfungsi sebagai diafragma, dan untuk menahan gaya geser yang terjadi antar voided slab sebagai akibat dari beban roda kendaraan yang bekerja pada salah satu elemen voided slab digunakan grouting dengan bahan mortar cement.

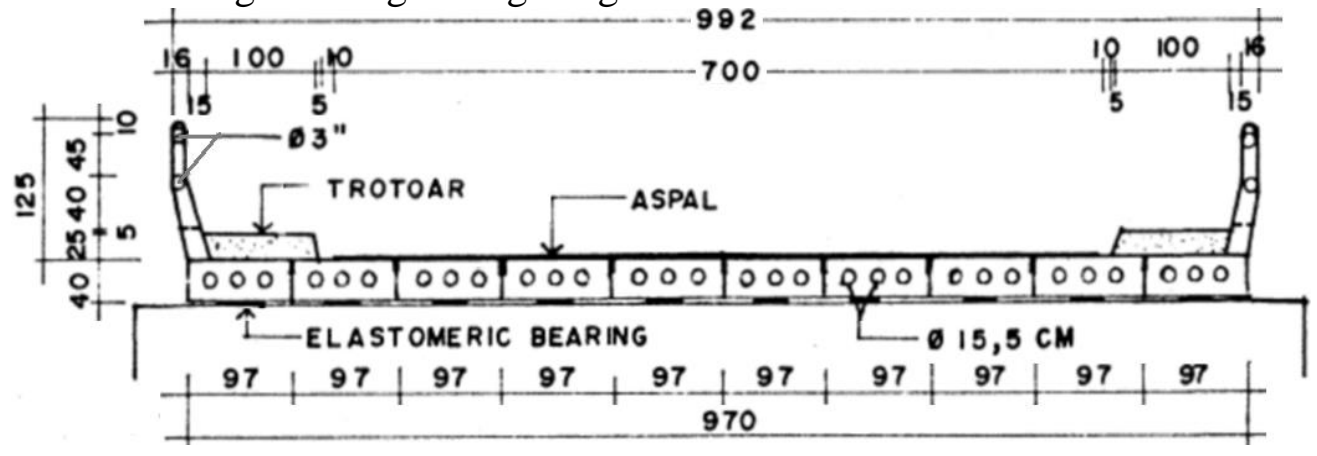

Gambar 2. Penampang jembatan type voided slab (Standard Konstruksi Jembatan Tipe Pretensioned Precast Concrete Voided Slab)

b. Beban Hidup Lalu Lintas

Mengacu kepada SNI 1725:2016, beban hidup lalu lintas untuk peninjauan gelagar adalah rangkaian beban roda kendaraan (T) dan beban D (beban BGT dan BTR), pilih mana yang mempengaruhi. Beban $\mathrm{T}$ adalah beban roda truk dengan bidang sentuh seluas $(25 \times 75) \mathrm{cm} 2$. Beban truk "T" tidak dapat digunakan bersamaan dengan beban "D". Beban garis terpusat (BGT) dengan intensitas $\mathrm{p} \mathrm{kN} / \mathrm{m}$ harus ditempatkan tegak lurus terhadap arah lalu lintas pada jembatan. Besarnya intensitas $\mathrm{p}$ adalah $49,0 \mathrm{kN} / \mathrm{m}$. Beban terbagi rata (BTR) mempunyai intensitas $\mathrm{q} \mathrm{kPa}$ dengan besaran $\mathrm{q}$ tergantung pada panjang total yang dibebani (L). Jika $\mathrm{L} \leq 30 \mathrm{~m}$ : maka $\mathrm{q}=9,0 \mathrm{kPa}$, Jika $\mathrm{L}>30 \mathrm{~m}$ : maka $\mathrm{q}=$ $9,0(0,5+(15 / \mathrm{L})) \mathrm{kPa}$.

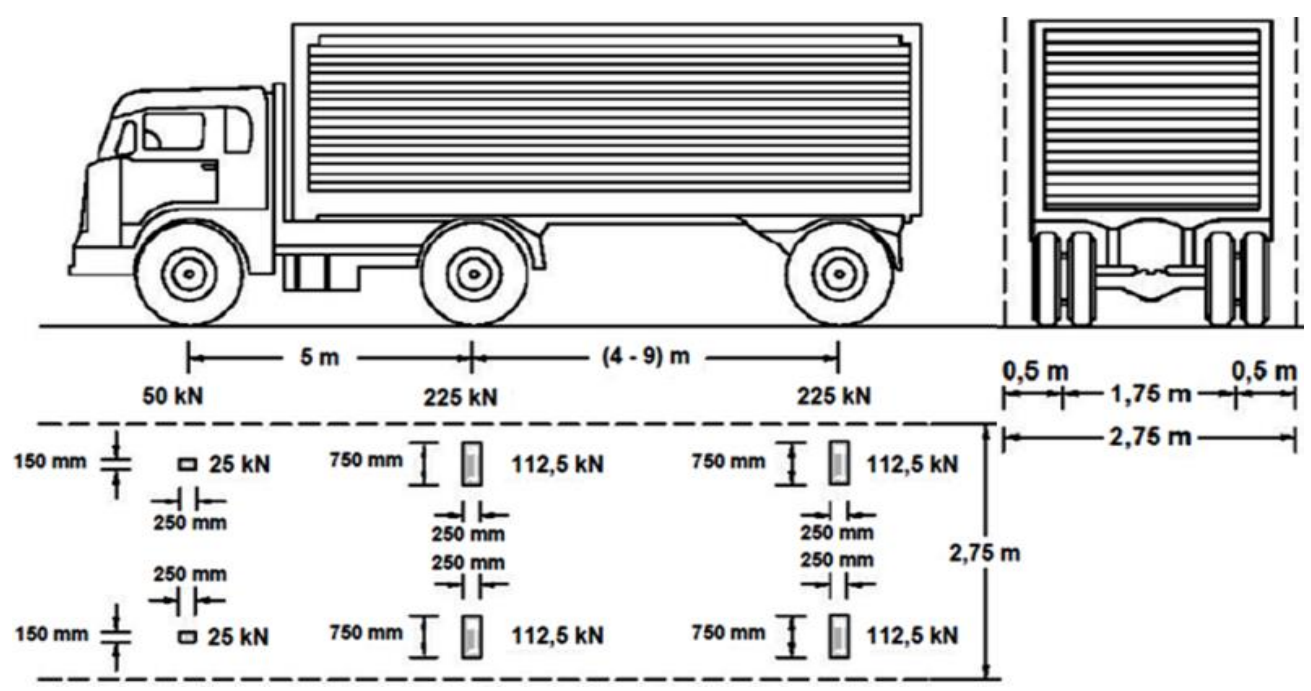

Gambar 3. Distribusi beban hidup T 


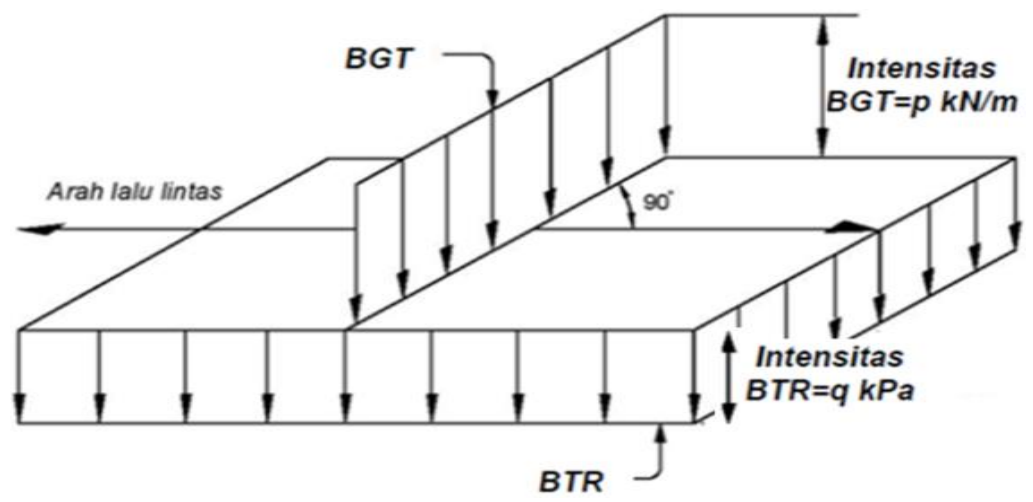

Gambar 4. Distribusi beban D

c. Kontrol tegangan kondisi akhir saat beban hidup bekerja

Tegangan di tengah bentang:

beban yang diperhitungkan : DL Voided slab, Aspal, beban Hidup dan Pe

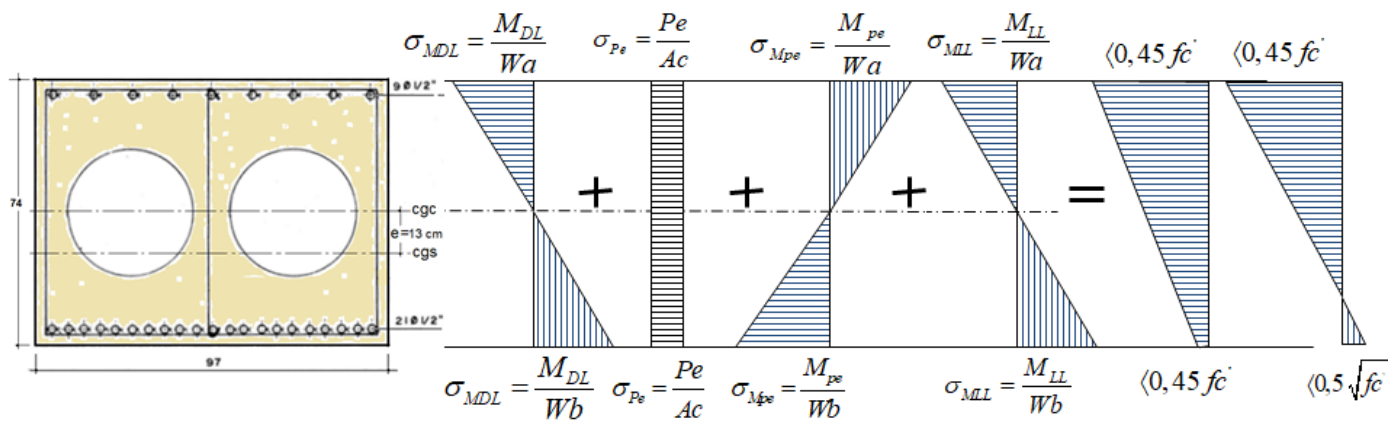

Gambar 5. Tegangan kondisi akhir saat beban hidup bekerja.

Tegangan beton sisi atas: $f t=\frac{M_{D L}}{W a}+\frac{P e}{A c}+\frac{M p e}{W a}+\frac{M_{L L}}{W a} \leq 0,45 f c^{\prime}$

Tegangan beton sisi bawah : $f b=\frac{M_{D L}}{W a}+\frac{P e}{A c}+\frac{M p e}{W a}+\frac{M_{L L}}{W a} \leq 0,5 x \sqrt{f c^{\prime}}$

\section{METODE PENELITIAN}

\subsection{Metoda pengumpulan data.}

Data yang dikumpulkan adalah data primer dan data sekunder. Data primer didapatkan dari hasil pengujian dilapangan terhadap struktur voided slab yang lantainya mengalami kerusakan dan yang tidak terjadi kerusakan. Data sekunder yang dikumpulkan adalah: Gambar Standar voided slab, data jembatan voided slab yang mengalami kerusakan, data berat kendaraan yang melewati jembatan, dan ukuran kendaraan standar yang beroperasi di jalan raya yang melewati jembatan. 


\subsection{Flow chart Kegiatan}

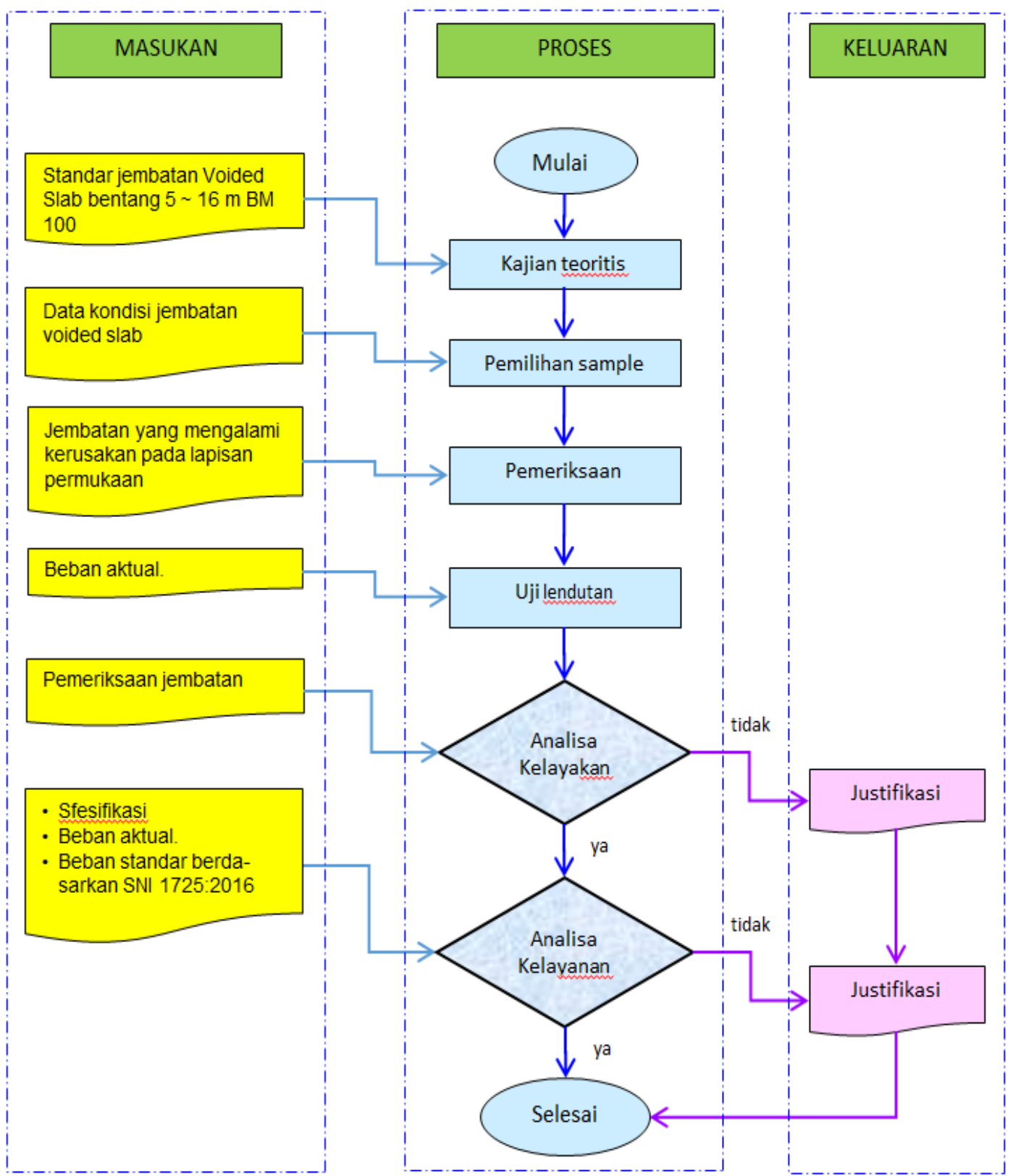

Gambar 6. Diagram alir penelitian

\subsection{Analisa data dan Pembahasan}

Analisa data dilakukan dengan menjustifikasi kelayakan struktur voided slab yang mengalami kerusakan yang didasarkan pada hasil uji dan pemeriksaan. Analisa data juga dilakukan untuk menentukan kelayanan struktur terhadap beban beban yang bekerja. Analisa kelayanan dilakukan terhadap struktur yang mengalami kerusakan dan yang tidak mengalami kerusakan. 


\section{HASIL DAN PEMBAHASAN}

\subsection{Hasil Pengumpulan Data Sekunder}

Tabel 1. Data jembatan voided slab yang mengalami kerusakan

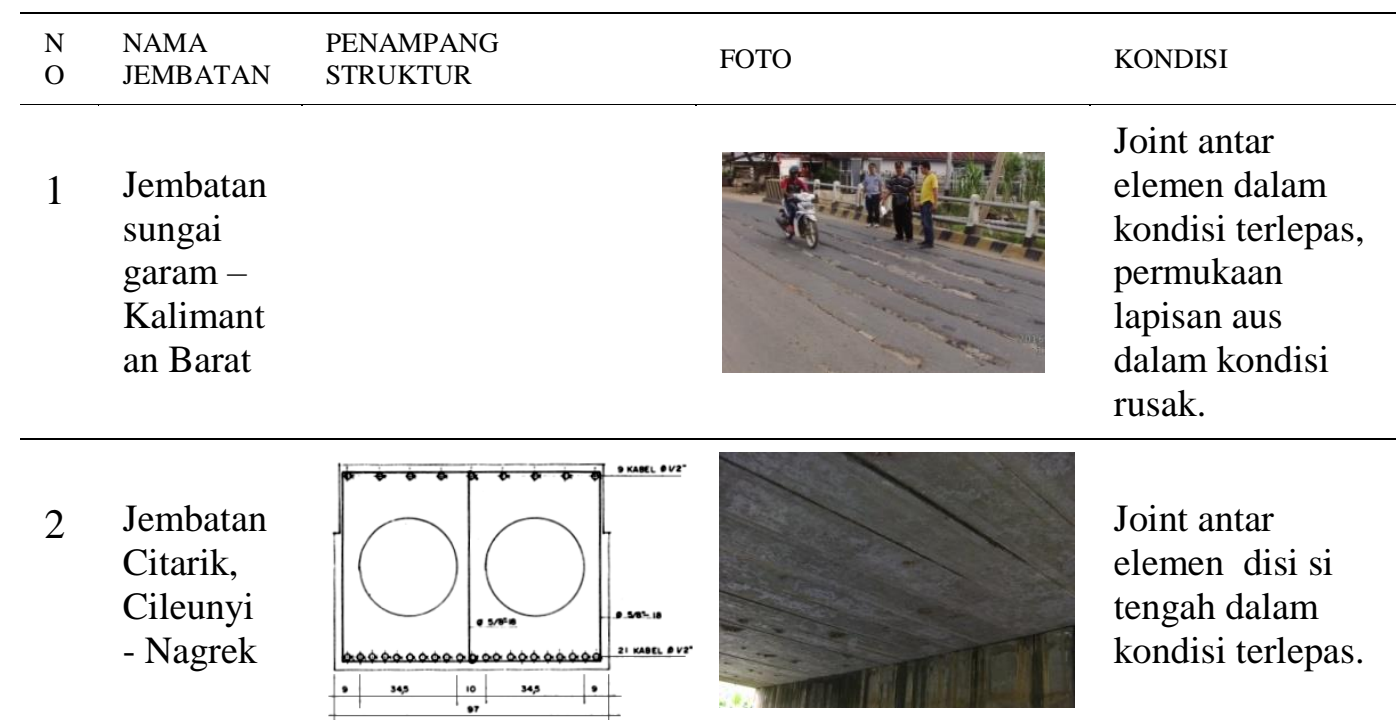

\subsection{Hasil Pengumpulan Data Primer}

Tabel 2. Pengujian elemen 8-9.

\begin{tabular}{|c|c|c|c|c|c|c|}
\hline NO & DATA & $\begin{array}{c}\text { NO } \\
\text { ELEMEN }\end{array}$ & $\begin{array}{l}\text { LENDUTAN } \\
\text { (MM) }\end{array}$ & $\begin{array}{c}\text { PERBEDAAN } \\
\text { LENDUTAN (MM) }\end{array}$ & $\begin{array}{l}\text { LENDUTAN } \\
\text { MAKSIMUM } \\
\text { (MM) }\end{array}$ & $\begin{array}{c}\text { PERBEDAAN } \\
\text { MAKSIMUM } \\
\text { (MM) }\end{array}$ \\
\hline \multirow{2}{*}{1} & \multirow{2}{*}{$\begin{array}{l}\text { FILE } \\
4911\end{array}$} & 8 & 1,36 & \multirow{2}{*}{1,85} & \multirow{18}{*}{13,34} & \multirow{18}{*}{8,9} \\
\hline & & 9 & 3,21 & & & \\
\hline \multirow{2}{*}{2} & \multirow{2}{*}{$\begin{array}{c}\text { File } \\
4914\end{array}$} & 8 & 5,62 & \multirow{2}{*}{4,07} & & \\
\hline & & 9 & 1,55 & & & \\
\hline \multirow{2}{*}{3} & \multirow{2}{*}{$\begin{array}{c}\text { File } \\
4915\end{array}$} & 8 & 4,84 & \multirow{2}{*}{1,15} & & \\
\hline & & 9 & 5,99 & & & \\
\hline \multirow{2}{*}{4} & \multirow{2}{*}{$\begin{array}{l}\text { File } \\
4935\end{array}$} & 8 & 1,17 & \multirow{2}{*}{4,82} & & \\
\hline & & 9 & 3,93 & & & \\
\hline \multirow{2}{*}{5} & \multirow{2}{*}{$\begin{array}{l}\text { File } \\
4938\end{array}$} & 8 & 10,38 & \multirow{2}{*}{1,28} & & \\
\hline & & 9 & 11,66 & & & \\
\hline \multirow{2}{*}{6} & \multirow{2}{*}{$\begin{array}{c}\text { File } \\
4926\end{array}$} & 8 & 1,89 & \multirow{2}{*}{0,26} & & \\
\hline & & 9 & 2,15 & & & \\
\hline \multirow{2}{*}{7} & \multirow{2}{*}{$\begin{array}{l}\text { File } \\
4940\end{array}$} & 9 & 13,34 & \multirow{2}{*}{8,9} & & \\
\hline & & 8 & 4,44 & & & \\
\hline \multirow{2}{*}{8} & \multirow{2}{*}{$\begin{array}{l}\text { File } \\
4909\end{array}$} & 8 & 4,09 & \multirow{2}{*}{0,69} & & \\
\hline & & 9 & 3,4 & & & \\
\hline \multirow{2}{*}{9} & \multirow{2}{*}{$\begin{array}{c}\text { File } \\
4903\end{array}$} & 8 & 0,85 & \multirow{2}{*}{0,5} & & \\
\hline & & 9 & 1,35 & & & \\
\hline
\end{tabular}


Tabel 3. Pengujian elemen 5-6.

\begin{tabular}{|c|c|c|c|c|c|c|}
\hline NO & DATA & $\begin{array}{c}\text { NO } \\
\text { ELEMEN }\end{array}$ & $\begin{array}{l}\text { LENDUTAN } \\
\quad(\mathrm{mm})\end{array}$ & $\begin{array}{l}\text { PERBEDAAN } \\
\text { LENDUTAN } \\
(\mathrm{mm})\end{array}$ & $\begin{array}{l}\text { LENDUTAN } \\
\text { MAKSIMUM } \\
(\mathrm{mm})\end{array}$ & $\begin{array}{l}\text { PERBEDAAN } \\
\text { MAKSIMUM } \\
(\mathrm{mm})\end{array}$ \\
\hline \multirow{2}{*}{1} & \multirow{2}{*}{ File 4963} & 5 & 2,01 & \multirow{2}{*}{0,76} & \multirow{18}{*}{5,79} & \multirow{18}{*}{0,76} \\
\hline & & 6 & 2,77 & & & \\
\hline \multirow{2}{*}{2} & \multirow{2}{*}{$\begin{array}{c}\text { Sanyo } \\
104\end{array}$} & 5 & 1,55 & \multirow{2}{*}{0,06} & & \\
\hline & & 6 & 1,61 & & & \\
\hline \multirow{2}{*}{3} & \multirow{2}{*}{$\begin{array}{c}\text { Sanyo } \\
117\end{array}$} & 5 & 0,39 & \multirow{2}{*}{0,25} & & \\
\hline & & 6 & 0,64 & & & \\
\hline \multirow{2}{*}{4} & \multirow{2}{*}{$\begin{array}{c}\text { Sanyo } \\
119\end{array}$} & 5 & 1,35 & \multirow{2}{*}{0,67} & & \\
\hline & & 6 & 2,02 & & & \\
\hline \multirow{2}{*}{5} & \multirow{2}{*}{$\begin{array}{c}\text { Sanyo } \\
121\end{array}$} & 5 & 5,05 & \multirow{2}{*}{0,74} & & \\
\hline & & 6 & 5,79 & & & \\
\hline \multirow{2}{*}{6} & \multirow{2}{*}{$\begin{array}{c}\text { Sanyo } \\
123\end{array}$} & 5 & 0,74 & \multirow{2}{*}{0,14} & & \\
\hline & & 6 & 0,88 & & & \\
\hline \multirow{2}{*}{7} & \multirow{2}{*}{$\begin{array}{c}\text { Sanyo } \\
126\end{array}$} & 5 & 1,08 & \multirow{2}{*}{0,35} & & \\
\hline & & 6 & 1,43 & & & \\
\hline \multirow{2}{*}{8} & \multirow{2}{*}{$\begin{array}{c}\text { Sanyo } \\
098\end{array}$} & 5 & 0,36 & \multirow{2}{*}{0,07} & & \\
\hline & & 6 & 0,43 & & & \\
\hline \multirow{2}{*}{9} & \multirow{2}{*}{$\begin{array}{c}\text { Sanyo } \\
088\end{array}$} & 5 & 2,24 & \multirow{2}{*}{0,39} & & \\
\hline & & 6 & 1,85 & & & \\
\hline
\end{tabular}

\subsection{Pembahasan}

a. Justifikasi kelayakan dan kelayanan hasil uji pembebanan

Kelayakan adalah sebutan yang digunakan untuk acuan pelayanan, apabila bangunan mengalami kerusakan atau bangunan yang tidak sesuai dengan spesifikasi yang telah ditetapkan, maka bangunan tersebut dinyatakan tidak layak untuk digunakan. Elemen elemen voided slab dinyatakan layak apabila antar elemen menyatu (tidak terpisah) satu sama lainnya. Bangunan yang tidak mampu menerima beban disebut tidak layan,.Untuk mengetahui kelayanan bangunan di lapangan, dilakukan dengan uji lendutan . Mengacu kepada buku "Panduan Penanganan Preservasi Jembatan", ISBN 978-602-97229-3-2, halaman 42, salah satu ukuran kelayanan struktur jembatan adalah lendutan akibat beban lalu lintas tidak terlampaui, dan mengacu kepada SNI 1725:2016 halaman 60, lendutan statis akibat getaran pada struktur atas jembatan dengan bentang $16 \mathrm{~m}$, tidak boleh lebih dari $7 \mathrm{~mm}$. 



Gambar 7. Diagram lendutan izin

Tabel 4. Justifikasi kelayakan

\begin{tabular}{|c|c|c|c|c|c|}
\hline NO & $\begin{array}{l}\text { VARIABEL } \\
\text { YANG } \\
\text { DI TINJAU }\end{array}$ & $\begin{array}{c}\text { NO. } \\
\text { ELEMEN }\end{array}$ & $\begin{array}{l}\text { PERBEDAAN } \\
\text { LENDUTAN } \\
(\mathrm{mm})\end{array}$ & DISKRIPSI & JUSTIFIKASI \\
\hline \multirow{2}{*}{1} & \multirow{2}{*}{$\begin{array}{l}\text { keintegras } \\
\text { ian antar } \\
\text { elemen } \\
\text { voided } \\
\text { slab }\end{array}$} & $5-6$ & $0,76 \mathrm{~mm}$ & $\begin{array}{l}\text { - Tidak terjadi } \\
\text { kerusakan ACWC } \\
\text { - Terintegrasi }\end{array}$ & Layak \\
\hline & & $8-9$ & $8,9 \mathrm{~mm}$ & $\begin{array}{l}\text { - Terjadi kerusakan } \\
\text { ACWC } \\
\text { - Tidak } \\
\text { Terintegrasi. }\end{array}$ & $\begin{array}{l}\text { Tidak } \\
\text { Layak }\end{array}$ \\
\hline
\end{tabular}

Tabel 5. Justifikasi kelayanan

\begin{tabular}{|c|c|c|c|c|c|c|}
\hline NO & $\begin{array}{l}\text { VARIABEL } \\
\text { YANG } \\
\text { DI TINJAU }\end{array}$ & $\begin{array}{c}\text { NO. } \\
\text { ELEMEN }\end{array}$ & $\begin{array}{l}\text { BATASAN } \\
\text { LENDUTAN } \\
(\mathrm{mm})\end{array}$ & $\begin{array}{l}\text { LENDUTAN } \\
\text { HASIL UJI } \\
(\mathrm{mm})\end{array}$ & DISKRIPSI & JUSTIFIKASI \\
\hline \multirow{2}{*}{1} & \multirow{2}{*}{$\begin{array}{l}\text { lendutan } \\
\text { di tengah } \\
\text { bentang } \\
\text { oleh } \\
\text { beban } \\
\text { aktual } \\
\text { berjalan }\end{array}$} & $5-6$ & 7 & 5,79 & $\begin{array}{l}\text { Struktur } \\
\text { terintegrasi, } \\
\text { lendutan hasil uji } \\
\text { dibawah } \\
\text { lendutan yang di } \\
\text { ijinkan. }\end{array}$ & Layan \\
\hline & & $8-9$ & 7 & 13,34 & $\begin{array}{l}\text { Struktur tidak } \\
\text { terintegrasi, dan } \\
\text { lendutan yang } \\
\text { terjadi diatas } \\
\text { lendutan yang di } \\
\text { ijinkan. }\end{array}$ & $\begin{array}{l}\text { Tidak } \\
\text { Layan }\end{array}$ \\
\hline
\end{tabular}

b. Analisa kelayanan

Analisa kelayanan dilakukan terhadap elemen voided slab yang menyatu dan yang terpisah, dengan tinjauan beban aktual yang mungkin terjadi dan beban standar sesuai dengan SNI 1725:2016. 


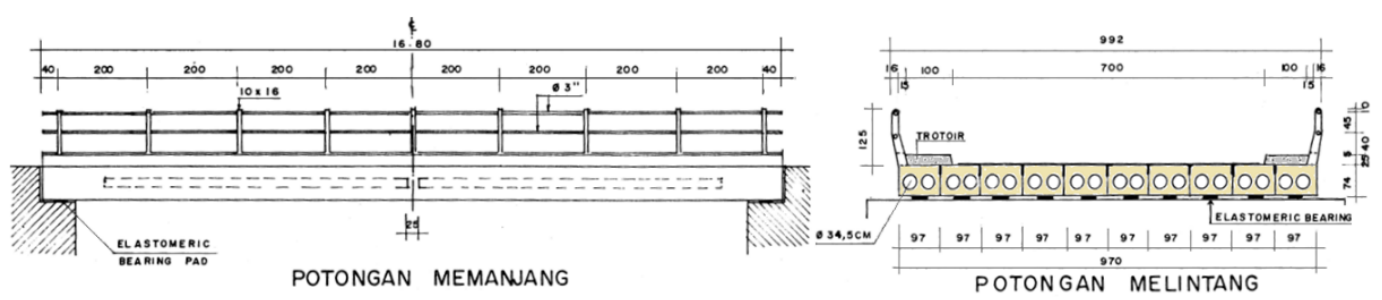

Gambar 8. Struktur voided slab yang dianalisa

Tinjauan dilakukan dengan pembebanan rangkaian truk (T) dan beban D

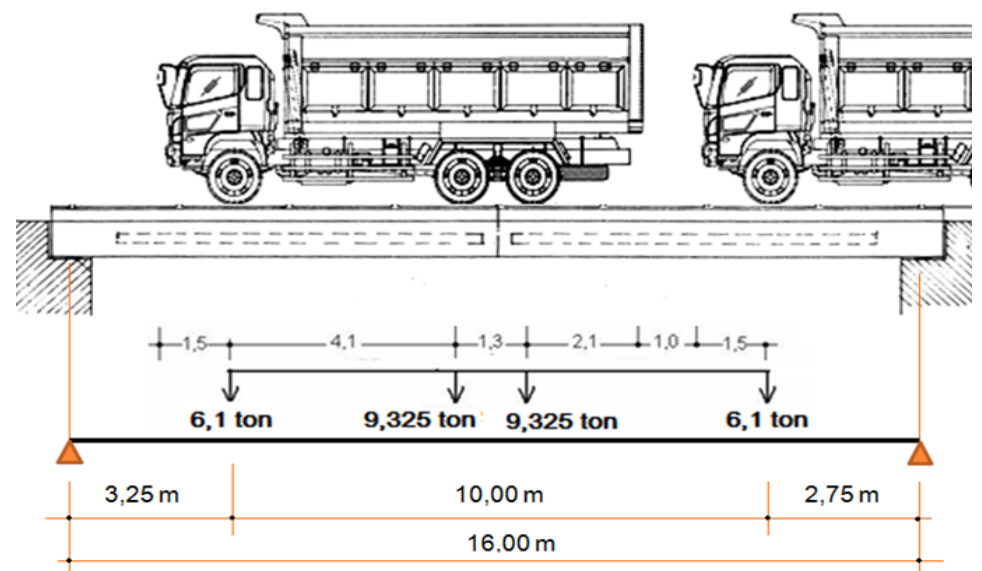

Gambar 9. Rangkaian beban truk aktual

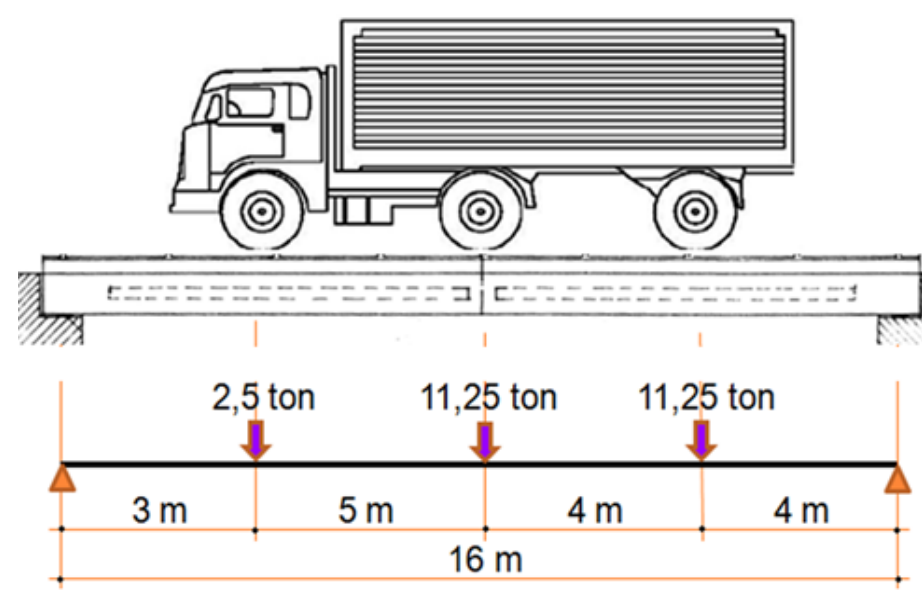

Gambar 10. Beban T standar 


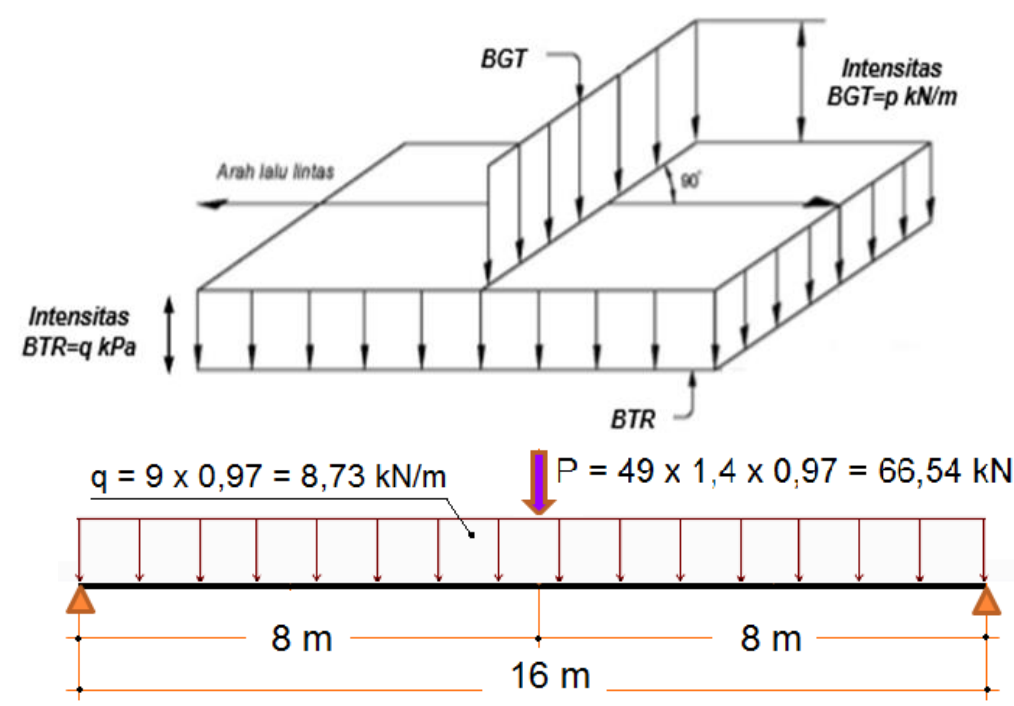

Gambar 11. Beban D standar

Hasil analisa dituangkan dalam tabel berikut:

Tabel 6. Analisa kelayanan

\begin{tabular}{|c|c|c|c|c|c|}
\hline NO & $\begin{array}{l}\text { KONDISI } \\
\text { STRUKTUR }\end{array}$ & $\begin{array}{l}\text { VARIABEL YANG DI } \\
\text { TINJAU }\end{array}$ & BATASAN & $\begin{array}{l}\text { HASIL } \\
\text { ANALISIS }\end{array}$ & $\begin{array}{l}\text { KESIM } \\
\text { PULAN }\end{array}$ \\
\hline \multirow{3}{*}{1} & \multirow{3}{*}{$\begin{array}{l}\text { Elemen } \\
\text { tidak ter- } \\
\text { intregasi, } \\
\text { dengan } \\
\text { beban truk } \\
\text { Aktual }\end{array}$} & $\begin{array}{l}\text { Lendutan akibat } \\
\text { LL ditengan } \\
\text { bentang }\end{array}$ & $20 \mathrm{~mm}$ & $36,2 \mathrm{~mm}$ & $\begin{array}{l}\text { Tidak } \\
\text { layan }\end{array}$ \\
\hline & & $\begin{array}{l}\text { Tegangan serat } \\
\text { atas }\end{array}$ & $\begin{array}{l}+28,5 \mathrm{~s} / \mathrm{d}-149 \\
\mathrm{~kg} / \mathrm{cm} 2\end{array}$ & $\begin{array}{l}-199,9 \\
\mathrm{~kg} / \mathrm{cm} 2\end{array}$ & $\begin{array}{l}\text { Tidak } \\
\text { layan }\end{array}$ \\
\hline & & $\begin{array}{l}\text { Tegangan serat } \\
\text { bawah }\end{array}$ & $\begin{array}{l}+28,5 \mathrm{~s} / \mathrm{d}-149 \\
\mathrm{~kg} / \mathrm{cm} 2\end{array}$ & $\begin{array}{l}+71,18 \\
\mathrm{~kg} / \mathrm{cm} 2\end{array}$ & $\begin{array}{l}\text { Tidak } \\
\text { layan }\end{array}$ \\
\hline \multirow{3}{*}{2} & \multirow{3}{*}{$\begin{array}{l}\text { Elemen } \\
\text { tidak ter- } \\
\text { intregasi, } \\
\text { dengan } \\
\text { beban truk } \\
\text { Standarl }(\mathrm{T})\end{array}$} & $\begin{array}{l}\text { Lendutan akibat } \\
\text { LL ditengan } \\
\text { bentang }\end{array}$ & $20 \mathrm{~mm}$ & $29,3 \mathrm{~mm}$ & $\begin{array}{l}\text { Tidak } \\
\text { layan }\end{array}$ \\
\hline & & $\begin{array}{l}\text { Tegangan serat } \\
\text { atas }\end{array}$ & $\begin{array}{l}+28,5 \mathrm{~s} / \mathrm{d}- \\
149 \mathrm{~kg} / \mathrm{cm} 2\end{array}$ & $\begin{array}{l}-173,88 \\
\mathrm{~kg} / \mathrm{cm} 2\end{array}$ & $\begin{array}{l}\text { Tidak } \\
\text { layan }\end{array}$ \\
\hline & & $\begin{array}{l}\text { Tegangan serat } \\
\text { bawah }\end{array}$ & $\begin{array}{l}+28,5 \mathrm{~s} / \mathrm{d}- \\
149 \mathrm{~kg} / \mathrm{cm} 2\end{array}$ & $\begin{array}{l}+45,16 \\
\mathrm{~kg} / \mathrm{cm} 2\end{array}$ & $\begin{array}{l}\text { Tidak } \\
\text { layan }\end{array}$ \\
\hline \multirow{3}{*}{2} & \multirow{3}{*}{$\begin{array}{l}\text { Elemen ter- } \\
\text { intregasi, } \\
\text { dengan } \\
\text { beban } \\
\text { Standar } \\
\text { BTG dan } \\
\text { BTR }\end{array}$} & $\begin{array}{l}\text { Lendutan akibat } \\
\text { LL ditengan } \\
\text { bentang }\end{array}$ & $20 \mathrm{~mm}$ & $16,7 \mathrm{~mm}$ & Layan \\
\hline & & $\begin{array}{l}\text { Tegangan serat } \\
\text { atas }\end{array}$ & $\begin{array}{l}+28,5 \mathrm{~s} / \mathrm{d}- \\
149 \mathrm{~kg} / \mathrm{cm} 2\end{array}$ & $\begin{array}{l}-128,37 \\
\mathrm{~kg} / \mathrm{cm} 2\end{array}$ & Layan \\
\hline & & $\begin{array}{l}\text { Tegangan serat } \\
\text { bawah }\end{array}$ & $\begin{array}{l}+28,5 \mathrm{~s} / \mathrm{d}- \\
149 \mathrm{~kg} / \mathrm{cm} 2\end{array}$ & $\begin{array}{l}-0,35 \\
\mathrm{~kg} / \mathrm{cm} 2\end{array}$ & Layan \\
\hline
\end{tabular}




\section{KESIMPULAN}

a) Hasil uji di lapangan menunjukkan bahwa elemen struktur voided slab yang awalnya menyatu, oleh sesuatu sebab dapat menjadi tidak menyatu. Sebagai akibat dari tidak menyatunya elemen-elemen voided slab, maka struktur terindikasi tidak layak, karena adanya kerusakan pada permukaan lantai jembatan, berupa lapisan aspal yang terkelupas dan terbentuknya alur memanjang pada lantai jembatan.

b) Elemen struktur voided slab yang awalnya menyatu dan oleh sesuatu sebab menjadi tidak menyatu, berdasarkan hasil pengujian dengan pembebanan secara acak menunjukkan lendutan sebesar $13,34 \mathrm{~mm}$, dan lendutan ini diatas lendutan maksimum yang diijinkan sebesar $7 \mathrm{~mm}$, sehingga struktur terdiskripsi tidak layan.

c) Dari hasil analisa teoritis pada elemen struktur voided slab yang antar elemennya tidak menyatu, menunjukkan bahwa struktur menjadi tidak layan, baik yang dibebani dengan rangkaian beban aktual terbesar yang mungkin terjadi atau yang dibebani dengan beban truck standart sesuai dengan peraturan pembebanan SNI 1725:2016.

d) Hasil analisa pada elemen voided slab yang antar elemennya menyatu, yang dibebani dengan beban standart sesuai dengan peraturan pembebanan SNI 1725:2016, menunjukkan bahwa struktur dalam kondisi layan.

\section{UCAPAN TERIMAKASIH}

Terima kasih yang tak terhingga saya sampaikan kepada semua fihak yang berperan aktif dalam proses penelitian, terutama para ahli jembatan dari Direktorat Jembatan kementerian PUPR, dan para mahasiswa program studi PJJ, jurusan teknik SIPIL, Politeknik Negeri Jakarta.

\section{DAFTAR PUSTAKA}

[1] Anoname. 2016. SNI Pembebanan Untuk Jembatan, No.SNI.1725:2016. Badan Standarisasi Nasional, Jakarta.

[2] Anoname. 2004. SNI Perencanaan Struktur Beton Untuk Jembatan, No.RSNI T12-2004. Badan Standar Nasional, Jakarta.

[3] Anoname. 2011. Manual Perencanaan Struktur Beton Prategang Untuk Jembatan, no. 021/BM/2011. Direktorat Jenderal Bina Marga, Kementrian Pekerjaan Umum, Jakarta.

[4] Anoname. 2011. Pedoman Pemeriksaan Jembatan, No.005-01/P/BM/2011. Direktorat Jenderal Bina Marga, Kementerian Pekerjaan Umum, Jakarta.

[5] Anoname. 1980. Standard Konstruksi Jembatan Type Pretensioned Precast Concrete Voided Slab, B.P.Pr - 100-Vs. Direktorat Jenderal Bina Marga, Departemen Pekerjaan Umum, Jakarta.

[6] Anoname. 1980. Standard Bangunan Atas jembatan Voided Slab Bentang 16 Meter. Direktorat Jenderal Bina Marga, Kementrian Pekerjaan Umum, Jakarta. 
[7] Ahamed Noura Ismail. 2017. Analysis and Design of Voided Slabbridge. International Journal of Research in Engineering and Technology, eISSN: 23191163, pISSN: 2321-7308, Karnataka, India.

[8] Behairy El. 2018. Behaviour and analysis of voided concrete slabs. ETH Zürich.

[9] Vaza, Herry dkk. 2010. Panduan Penanganan Preservasi Jembatan. Direktorat Jenderal Bina Marga, Kementrian Pekerjaan Umum, Jakarta. 